\title{
Does disallowing body checking in non-elite 13- to 14-year-old ice hockey leagues reduce rates of injury and concussion? A cohort study in two Canadian provinces
}

\author{
Carolyn Emery (이, 1,2 Luz Palacios-Derflingher, ${ }^{1,2}$ Amanda Marie Black (1) , \\ Paul Eliason, ${ }^{1}$ Maciek Krolikowski, ${ }^{1}$ Nicole Spencer, ${ }^{1}$ Stacy Kozak, ${ }^{1}$ \\ Kathryn J Schneider, ${ }_{1}^{1}$ Shelina Babul, ${ }^{3}$ Martin Mrazik, ${ }_{1}^{4}$ Constance M Lebrun, ${ }^{5}$ \\ Claude Goulet, ${ }^{6}$ Alison Macpherson, ${ }^{7}$ Brent E Hagel ${ }^{8}{ }^{8}$
}

${ }^{1}$ Sport Injury Prevention Research Centre, Faculty of Kinesiology, University of Calgary, Calgary, Alberta, Canada

${ }^{2}$ Community Health Sciences, Cumming School of Medicine, University of Calgary, Calgary, Alberta, Canada

${ }^{3}$ Faculty of Medicine, University of British Columbia, Vancouver, Alberta, Canada

${ }^{4}$ Department of Educational

Psychology, Faculty of Education, University of Alberta, Edmonton, Alberta, Canada ${ }^{5}$ Depatment of Family Medicine, Faculty of Medicine and Dentistry, University of Alberta, Edmonton, Alberta, Canada ${ }^{6}$ Department of Physical Education, Laval University, Quebec, Quebec, Canada ${ }^{7}$ Faculty of Health, York University, Toronto, Ontario, Canada

${ }^{8}$ Department of Paediatrics, Cumming Scjhool of Medicine, University of Calgary, Calgary, Alberta, Canada

\section{Correspondence to} Dr Carolyn Emery, Kinesiology, University of Calgary, Calgary, Alberta T2N1N4, Canada; caemery@ucalgary.ca

Accepted 2 September 2019 Published Online First 6 September 2019

\section{Check for updates}

(C) Author(s) (or their employer(s)) 2020. No commercial re-use. See rights and permissions. Published by BMJ.

To cite: Emery C, PalaciosDerflingher L, Black AM, et al. Br J Sports Med 2020;54:414-420.

\section{ABSTRACT}

Objective To compare rates of injury and concussion among non-elite (lowest $60 \%$ by division of play) Bantam (ages 13-14 years) ice hockey leagues that disallow body checking to non-elite Bantam leagues that allow body checking.

Methods In this 2-year cohort study, Bantam nonelite ice hockey players were recruited from leagues where policy allowed body checking in games (Calgary/ Edmonton 2014-2015, Edmonton 2015-2016) and where policy disallowed body checking (Kelowna/ Vancouver 2014-2015, Calgary 2015-2016). All ice hockey game-related injuries resulting in medical attention, inability to complete a session and/or time loss from hockey were identified using valid injury surveillance methodology. Any player suspected of having concussion was referred to a study physician for diagnosis and management.

Results 49 body checking (608 players) and 33 nonbody checking teams (396 players) participated. There were 129 injuries (incidence rate $(I R)=7.98 / 1000$ hours) and 54 concussions ( $I R=3.34 / 1000$ hours) in the body checking teams in games. After policy change, there were 31 injuries (IR=3.66/1000 hours) and 17 concussions $(I R=2.01 / 1000$ hours) in games. Policy disallowing body checking was associated with a lower rate of all injury (adjusted incidence rate ratio (IRR) $=0.44 ; 95 \% \mathrm{Cl}: 0.27$ to 0.74$)$. The point estimate showed a lower rate of concussion (adjusted IRR=0.6; 95\% Cl: 0.31 to 1.18), but this was not statistically significant.

Conclusion Policy change disallowing body checking in non-elite Bantam ice hockey resulted in a $56 \%$ lower rate of injury. There is growing evidence that disallowing body checking in youth ice hockey is associated with fewer injuries.

\section{INTRODUCTION}

In Canada, >500000 youth (ages 10-19 years) participate in ice hockey annually. ${ }^{1}$ Participating in a team sport has many benefits, including improving physical fitness, self-esteem and mental health. ${ }^{2-4}$ However, youth ice hockey has a high burden of injury. ${ }^{5}$ Sport is the leading cause of injury in youth, accounting for $>60 \%$ of all concussions. Annually, one in ten youth will sustain a sportrelated concussion. ${ }^{8}$ Ice hockey accounts for the highest proportion of injuries reported to an emergency room compared with other sports in Canada (ages 5-19 years). ${ }^{9}$

In youth ice hockey, the rate of injury and concussion are among the highest in youth sport, with rates of injury as high as six injuries/1000 gamehours and 2.79 concussions/1000 game-hours in leagues allowing body checking. ${ }^{7}{ }^{10-19}$ Body checking is a tactic used to gain an advantage on the opponent with the use of the body and occurs when a player intentionally plays the body of the opponent (contacts an opponent forcefully) to stop an attack or separate the opponent from the puck. ${ }^{20}$ Prior to policy change disallowing body checking in Pee Wee (ages 11-12 years), the concussion rate (1.47 concussions/1000 player-hours) was similar to that in the professional National Hockey League (1.8 concussions per/1000 player-hours). ${ }^{1421}$ The reported rate of concussion in youth has increased over the past decade due to increased awareness of concussion, media attention and international guideline awareness. ${ }^{19} 22$

Our research has informed policy change that disallowed body checking in Pee Wee leagues nationally (USA 2011, Canada 2013) and in nonelite levels of play (lower $60 \%$ by division of play) in older age groups (ages 13-17 years). ${ }^{1012-17}$ The appropriate age to introduce body checking has been a topic of debate for 30 years. After a policy was implement to disallow body checking in Pee Wee, injury rates fell by more than 50\%.$^{10}{ }^{14-17} \mathrm{~A}$ recent meta-analysis reported a combined unadjusted $67 \%$ lower (incidence rate ratio $($ IRR $)=0.33$; 95\% CI: 0.25 to 0.45 ) concussion risk in Pee Wee leagues where policy disallows body checking. ${ }^{12}$

Advocates for permitting body checking in Pee Wee argue that gaining body checking experience in Pee Wee may protect youth who subsequently play in Bantam (ages 13-14 years). A cohort study in Pee Wee, however, did not reveal a difference in risk of all injury (IRR $=0.85$; 95\% CI: 0.63 to 1.16 ) or concussion (IRR $=0.84$; (95\% CI: 0.48 to 1.48 ) between those with and without body checking experience in Pee Wee when they subsequently played in Bantam. ${ }^{18}$ The rate of severe injury ( $>7$ days time loss) in Bantam was 33\% lower among the players who had body checking experience in 
Pee Wee than among those who did not. ${ }^{18}$ However, this finding should be considered in light of this body checking policy change reducing the rate of severe injury $70 \%$ in Pee Wee in leagues disallowing body checking.

The Canadian province of British Columbia disallowed body checking in non-elite Bantam leagues (60\% of players) prior to 2014 (2012-2013 season), and similar changes followed regionally in the neighbouring province of Alberta in 2015. These policy changes provided an opportunity for a prospective cohort study to answer the question-In non-elite levels of Bantam ice hockey, what effect does a change in body checking policy have on injury? The objective of this study was to examine changes in the rate of injury and concussion associated with a policy change that disallowed body checking in games in non-elite Bantam ice hockey.

\section{METHODS}

Design

This was a prospective cohort study conducted across four cities in two Canadian provinces (British Columbia (Vancouver, Kelowna), Alberta (Calgary, Edmonton)).

\section{Participants}

Non-elite Bantam ice hockey players (ages 13-14 years) in the lower $60 \%$ by division of play were recruited from Calgary and Edmonton in the 2014-2015 season when body checking was allowed at all levels of play across the province of Alberta. Players were recruited from Kelowna and Vancouver in the province of British Columbia where body checking was disallowed in 2014-2015. In the 2015-2016 season, players in Calgary were recruited when local policy disallowed body checking in nonelite Bantam. In 2015-2016, players were recruited in Edmonton where body checking was still allowed at all levels. (figure 1) An a priori sample size of 46 teams per cohort (13 players per team) was based on a Pee Wee cohort study. ${ }^{16}$ The anticipated difference between the two cohorts was powered based on an $\mathrm{IRR}=0.5$, concussion rate $=1.5 / 1000$ player-hours in the body checking cohort, 75.5 hours of exposure, a team coefficient variation of 0.58 (planned comparison of rates controlling for cluster by team) and adjusting for cluster $(\alpha=0.05, \beta=0.20)$. We anticipated 5\% dropout rate and thus aimed for 49 teams in each arm (body checking allowed vs body checking disallowed) was the aim for recruitment. ${ }^{16}$

Study cohorts were defined by their exposure to policy that allowed or disallowed body checking in non-elite Bantam ice hockey. Inclusion criteria were as follows: (1) players 13-14 years of age; (2) male or female players; (3) written informed player and parent consent; (4) players registered in Bantam with Hockey Calgary, Hockey Edmonton, BC Hockey; (5) players in the lower $60 \%$ by division of play; (6) agreement of the head coach and (7) agreement of a team designate (eg, manager) to

\begin{tabular}{|c|c|c|}
\hline & \multicolumn{2}{|c|}{ Year } \\
\hline & $2014 / 15$ & 2015/16 \\
\hline Calgary & & \\
\hline Edmonton & & \\
\hline Kelowna/Vancouver & & \\
\hline
\end{tabular}

Body checking allowed

Body checking disallowed

Figure 1 Body checking policy by year and region. collect player participation and injury information. Players were excluded if they (1) participated in a 'girls-only' league or (2) had a previous injury or illness that prevented full participation in hockey at the beginning of the season.

\section{Procedures}

Valid injury surveillance methodology included a preseason baseline questionnaire, Sport Concussion Assessment Tool, weekly exposure sheet (WES) and injury report form (IRF). ${ }^{22} 23$ Each team designate collected WES data and identified players with a suspected concussion or injury. A study athletic therapist followed-up on all injuries reported on an IRF or if a player WES indicated the player was absent due to injury, by phone and/or at physician follow-up. Details of injury surveillance methodology are reported in previous studies. ${ }^{15}$ 18-20 23 All ice hockey injuries resulting in medical attention, the inability to complete a session and/or time loss from hockey were identified by the team designate and recorded on an IRF. All players with a suspected concussion were given the opportunity to follow-up with a study sport medicine physician within 72 hours. Standardised follow-up and return to play protocols were followed by all study physicians based on the fourth International Consensus Statement on Concussion in Sport. ${ }^{22}$ Concussions were included if they met the definition for concussion based on the Consensus statement. ${ }^{22}$ Severe injuries were defined as those that resulted in $>1$ week missed from hockey and severe concussions defined were those that resulted in time loss from hockey $>10$ days. A 10-day time loss cut-point has been supported in the literature and allows comparisons with other studies. ${ }^{14}$ 17-19 22 24-28

\section{Analyses}

The statistical software R and STATA were used for all analyses. $^{29}{ }^{30}$ Baseline characteristics were stratified by body checking group and by players who sustained at least one injury in this study. When weekly game exposure was missing, imputation based on weekly means was performed within participant, or based on team information or within city and division as informed by previous youth ice hockey studies ${ }^{16-19}$ and methodological approach recommended by Kang et al (2014). ${ }^{31}$ Crude game-related rates were estimated for injury, severe injury, concussion and severe concussion for each study group and 95\% CIs were estimated considering clustering (offset by game-hours). Rate ratios (95\% CI) were estimated with Poisson regression with clustering by team (offset by game-hours). Absolute rate reductions (ARR) were calculated based on these rates. The estimates for the number of injuries and concussions saved in one season in Alberta and Canada were based on the ARR, using the average game-hours (38.75 game-hours) of non-elite Bantam players in one season in 2016-17 from Alberta (4461 players) and Canada (38152 players). ${ }^{32}$

Separate multiple multilevel Poisson regression models for game-related injury and concussion were used to evaluate the association between each outcome and body checking group, adjusting for important covariates: previous injury in the last year (for injury outcome), previous lifetime concussion (for concussion outcome), year of play (first or second), weight (categorisation in each model was based on the pattern observed between $\log$ (rate) and weight) when assumptions of linearity were not met), and position (Defence, Forward, Goalie). For concussion, Poisson regressions were run, including body checking group and one covariate at a time. The missing data were imputed using multiple imputation by chained equations; sensitivity analyses were performed with complete case analysis. City and year 
were not considered as they are specific to the body checking cohorts. Sex was not considered because of low numbers of female players. Game-hours was used as an offset, and team level and subject level random effects were examined in order to take into account the clustering at each level.

Crude rates for each location and type of injury were calculated; their 95\% CIs were estimated considering clustering (offset by game-hours). When the number of counts was low for model convergence, exact Poisson CIs were calculated.

\section{RESULTS}

In total, 944 non-elite Bantam ice hockey players were recruited from Calgary, Edmonton, Kelowna and Vancouver; of these, 60 players participated across both seasons. In all, 49 teams were recruited in leagues allowing body checking and 33 teams in leagues disallowing body checking across 2014-2015 and
2015-2016 seasons of play (see figure 1). The proportion of teams agreeing to participate was similar in the body checking (49/120) and non-body checking (33/115) cohorts. Additionally, the median number of players recruited per team was similar with 13 in body checking teams and 11 in non-body checking teams. There were 608 player-seasons in leagues allowing body checking (Calgary $(\mathrm{n}=153)$ and Edmonton $(\mathrm{n}=241)$ in 2014 2015; Edmonton $(\mathrm{n}=214)$ in 2015-2016) and 396 playerseasons in leagues disallowing body checking (Kelowna $(n=42)$ and Vancouver $(n=221)$ 2014-2015; Calgary $(n=133)$ in 20152016). Baseline characteristics by body checking cohort and injury status (at least one player injury) are summarised in table 1.

Participants were followed for 2-24 weeks (median of 19 weeks). Almost all participants (94.6\%) had at least 1 week of game exposure imputed. The median percentage of weeks imputed was $17 \%$ (first quartile: 10\%, third quartile: 36\%).

Table 1 Baseline characteristics

\begin{tabular}{|c|c|c|c|c|c|c|c|c|}
\hline & \multicolumn{4}{|c|}{ Body checking ( $n=49$ teams) } & \multicolumn{4}{|c|}{ No body checking ( $\mathrm{n}=33$ teams) } \\
\hline & \multicolumn{2}{|l|}{ Injured } & \multicolumn{2}{|c|}{ Not injured } & \multicolumn{2}{|l|}{ Injured } & \multicolumn{2}{|c|}{ Not injured } \\
\hline & \multicolumn{2}{|c|}{${ }^{*} \mathrm{n}=117$ players } & \multicolumn{2}{|c|}{${ }^{*} \mathrm{n}=491$ players } & \multicolumn{2}{|c|}{${ }^{*} \mathrm{n}=26$ players } & \multicolumn{2}{|c|}{${ }^{*} \mathrm{n}=370$ players } \\
\hline Calgary & 21 & 17.95 & 132 & 26.88 & 13 & 50.00 & 120 & 32.43 \\
\hline Edmonton & 96 & 82.05 & 359 & 73.12 & 0 & 0.00 & 0 & 0.00 \\
\hline $\begin{array}{l}\text { Vancouver and } \\
\text { Kelowna, British } \\
\text { Columbia }\end{array}$ & 0 & 0.00 & 0 & 0.00 & 13 & 50.00 & 250 & 67.57 \\
\hline \multicolumn{9}{|l|}{ Year, n (\%) } \\
\hline $2014-2015$ & 69 & 58.97 & 325 & 66.19 & 13 & 50.00 & 250 & 67.57 \\
\hline 2015-2016 & 48 & 41.03 & 166 & 33.81 & 13 & 50.00 & 120 & 32.43 \\
\hline \multicolumn{9}{|l|}{ Sex, n (\%) } \\
\hline Male & 113 & 96.58 & 484 & 98.57 & 26 & 100.00 & 364 & 98.38 \\
\hline Missing n (\%) & 17 & 14.53 & 92 & 18.73 & 4 & $(5.38$ & 82 & 22.16 \\
\hline $\begin{array}{l}\text { Weight, kg median } \\
(\mathrm{Q} 1, \mathrm{Q})\end{array}$ & 55.30 & $45.36,63.50$ & 53.50 & $45.40,61.23$ & 54.40 & $48.00,64.63$ & 54.40 & $45.40,63.50$ \\
\hline Missing & 23 & 19.66 & 106 & 21.59 & 7 & 26.92 & 101 & 27.30 \\
\hline \multicolumn{9}{|l|}{ Year of play, n (\%) } \\
\hline First & 61 & 52.13 & 268 & 54.58 & 14 & 53.85 & 181 & 48.92 \\
\hline Second & 49 & 41.88 & 206 & 41.96 & 9 & 34.62 & 160 & 43.24 \\
\hline Missing & 7 & 5.98 & 17 & 3.46 & 3 & 11.54 & 29 & 7.84 \\
\hline \multicolumn{9}{|l|}{ Position, n (\%) } \\
\hline Forward & 69 & 58.97 & 256 & 52.14 & 14 & 53.85 & 181 & 48.92 \\
\hline No & 69 & 58.97 & 334 & 68.02 & 13 & 50.00 & 239 & 64.59 \\
\hline Yes & 46 & 39.32 & 144 & 29.33 & 13 & 50.00 & 116 & 31.35 \\
\hline Missing data & 2 & 1.71 & 13 & 2.65 & 0 & 0.00 & 15 & 4.05 \\
\hline
\end{tabular}

Q1: first quartile Q3: third quartile.

*Sum of $\mathrm{n}$ is 1004 , given that it is player-season (60 players participated in two seasons).

tPrevious injury or concussion 12 months prior to baseline test.

‡Previous concussion ever. 


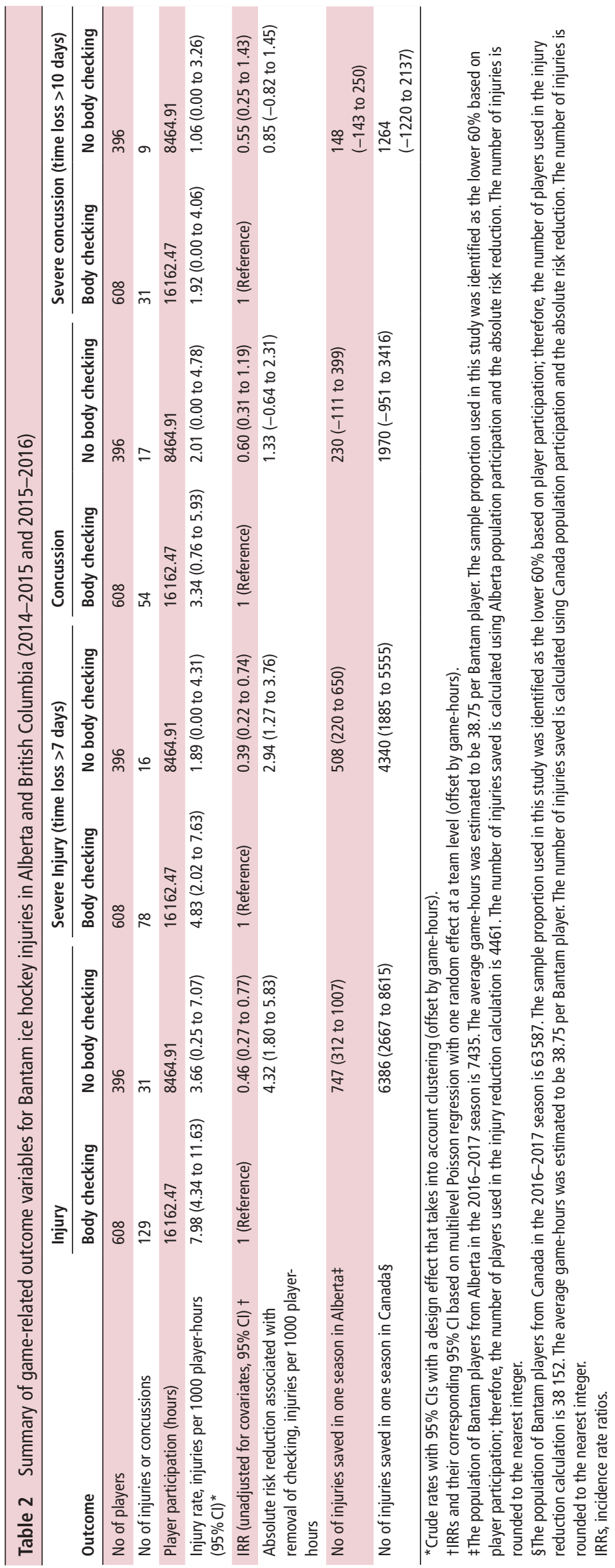


In non-elite levels of Bantam, policy disallowing body checking was associated with a $54 \%$ lower rate of all injury (IRR $=0.46$; 95\% CI: 0.27 to 0.77 ) (table 2), and a 61\% lower rate of severe injury $(\mathrm{IRR}=0.39 ; 95 \% \mathrm{CI}: 0.22$ to 0.74$)$. There was a $40 \%$ lower rate of concussion $(\mathrm{IRR}=0.6 ; 95 \% \mathrm{CI}$ : 0.31 to 1.19 ) and $45 \%$ lower rate of severe concussion $(\mathrm{IRR}=0.55 ; 95 \% \mathrm{CI}$ : 0.25 to 1.43 ), but these effects were not statistically significant. (table 2).

The median time loss following concussion was 12.5 days (first quartile: 7 , third quartile: 20 ) in the body checking cohort and 15 days (first quartile: 2, third quartile: 21) in the nonbody checking cohort. Based on ARR and Alberta and Canada population estimates, 747 injuries (95\% CI: 312 to 1007) and 508 severe injuries (time loss $>7$ days) (95\% CI: 220 to 650 ) would have been prevented in Alberta in non-elite Bantam in one season if body checking was disallowed across the province; and 6386 injuries (95\% CI: 2667 to 8615 ) and 4340 severe injuries (95\% CI 1885 to 5555 ) in Canada if body checking was disallowed nationally (table 2 ).

The results of the adjusted multilevel Poisson models for each game outcome (game injury (model with two random effects, one at a team level and one at a subject level) and game concussion (model with one random effect at a team level)) to evaluate the association between each outcome and body checking group, adjusting for important covariates, are summarised in table 3 . Policy disallowing body checking was associated with a $56 \%$ lower rate of all injury (IRR $=0.44 ; 95 \% \mathrm{CI}: 0.27$ to 0.74 ) and policy disallowing body checking showed a $40 \%$ lower rate of concussion (IRR $=0.6 ; 95 \% \mathrm{CI} ; 0.31$ to 1.18 ) that was not statistically significant (table 3).

For all injuries, larger players by weight $\left(\operatorname{IRR}_{80-109 \mathrm{~kg} \text { vs } 60-80}\right.$ $\mathrm{kg}=2.64 ; 95 \%$ CI: 1.03 to 6.79 ) had a greater rate of injury and goalies were protected (IRR $=0.24 ; 95 \% \mathrm{CI}$ : 0.07 to 0.77 ) compared with defence players; the IRR for previous injury history had a point estimate of 1.42 (95\% CI: 0.98 to 2.06), which was not statistically significant (table 3 ). The point estimate showed that previous concussion $(\mathrm{IRR}=1.53$; 95\% CI: 0.94 to 2.48) was a risk factor for subsequent concussion, but this effect was not statistically significant (table 3 ).

Similar results and interpretations were seen in the estimates based on the sensitivity analysis for injury. There were also similarities for concussion, except for weight, where there was a significant association in the complete case analysis (weight had $24 \%$ missing observations).

The head/face was the most common location of injury in both cohorts (table 4). The number of injuries to the shoulder/clavicle was markedly higher among body checking teams. Concussion was the most common injury type among both cohorts, followed by fractures in body checking teams and contusions in the nonbody checking teams.

\section{DISCUSSION}

This is the first cohort study to examine policy change where body checking was disallowed in non-elite Bantam ice hockey compared with leagues where body checking was allowed. Policy change that disallowed body checking in non-elite Bantam ice hockey resulted in a 54\% lower rate in game injuries and 61\% lower rate in severe game injuries. Although not statistically significant, a clinically relevant $40 \%$ lower rate in game concussion rate was also seen.

The impact of this policy change in non-elite Bantam is similar to that found in Pee Wee following similar policy change nationally in 2013, with a 50\% lower injury rate and a $60 \%$ lower
Table 3 Association between potential risk factors and game-related injury, and with concussion in Bantam ice hockey players in Alberta and British Columbia (2014-2015 and 2015-2016) in the lower 60\% by division of play (with MICE imputation)

\begin{tabular}{|c|c|c|c|c|}
\hline \multirow{2}{*}{$\begin{array}{l}\text { Risk factor } \\
\text { Body } \\
\text { checking } \\
\text { group }\end{array}$} & & \multirow{2}{*}{$\begin{array}{l}\text { All injury adjusted* } \\
\text { IRRs }(95 \% \mathrm{Cl})\end{array}$} & \multicolumn{2}{|c|}{ Concussion adjusted $t$} \\
\hline & & & \multicolumn{2}{|l|}{ IRRs $(95 \% \mathrm{Cl})$} \\
\hline & $\begin{array}{l}\text { Body } \\
\text { checking }\end{array}$ & 1 (Reference) & \multicolumn{2}{|l|}{1 (Reference) } \\
\hline & $\begin{array}{l}\text { Non-body } \\
\text { checking }\end{array}$ & 0.44 (0.27 to 0.74$)$ & \multicolumn{2}{|c|}{0.60 (0.31 to 1.18$) \ddagger$} \\
\hline \multicolumn{5}{|l|}{ Year of play } \\
\hline & First & 1 (Reference) & \multicolumn{2}{|l|}{1 (Reference) } \\
\hline & Second & $0.96(0.73$ to 1.27$)$ & \multicolumn{2}{|c|}{$1.06(0.74$ to 1.52$)$} \\
\hline \multicolumn{5}{|l|}{ Player size§ } \\
\hline & $20<40 \mathrm{~kg}$ & 1.15 (0.58 to 2.28$)$ & $20<70 \mathrm{Kg}$ & 1 (Reference) \\
\hline & $40<60 \mathrm{~kg}$ & 1.02 (0.64 to 0.61$)$ & 70 to $109 \mathrm{Kg}$ & $\begin{array}{l}1.85(0.91 \text { to } \\
3.76)\end{array}$ \\
\hline & $60<80 \mathrm{~kg}$ & 1 (Reference) & & \\
\hline & $80-109 \mathrm{~kg}$ & $2.64(1.03$ to 6.79$)$ & & \\
\hline \multicolumn{5}{|c|}{ Previous injury in the last year (including concussion) } \\
\hline & No & 1 (Reference) & \multicolumn{2}{|l|}{ NA } \\
\hline & Yes & 1.42 (0.98 to 2.06$)$ & \multicolumn{2}{|l|}{ NA } \\
\hline \multicolumn{5}{|c|}{ Previous concussion (any concussion, no date limit) } \\
\hline & No & NA & \multicolumn{2}{|l|}{1 (Reference) } \\
\hline & Yes & NA & \multicolumn{2}{|c|}{1.53 (0.94 to 2.48$)$} \\
\hline \multicolumn{5}{|l|}{ Position } \\
\hline & Defence & 1 (Reference) & \multicolumn{2}{|l|}{1 (Reference) } \\
\hline & Goalie & 0.24 (0.07 to 0.77$)$ & \multicolumn{2}{|c|}{0.19 (0.03 to 1.43$)$} \\
\hline & Forward & 1.01 (0.69 to 1.48$)$ & \multicolumn{2}{|c|}{1.01 (0.6 to 1.7$)$} \\
\hline
\end{tabular}

*IRRs based on multilevel Poisson regression analysis with two random effects: one at a team level and one at a subject level, offset for exposure hours and adjusted for covariates (body checking, year of play, previous injury/concussion in the last year, player size and position).

tIRRs based on multilevel Poisson regressions (two covariates included in each model: body checking group included in all models, plus one other covariate from the table) with one random effect at a team level, owing to fewer injuries, offset for exposure hours.

FIRR based on multilevel Poisson regression with one random effect at a team level and adjusted for previous history of concussion. IRRs from the other models were similar.

$\S$ Categories for player size were based on the linear relation between the outcome and player size.

IRRs, incidence rate ratios; MICE, multiple imputation by chained equations.

severe injury rate in games. ${ }^{17}$ The impact of body checking policy on concussion in non-elite Bantam players was lower than that found in Pee Wee players (40\% vs $64 \%$ lower rate). ${ }^{17}$ For more severe concussion, the point estimates were similar with a $45 \%$ lower rate among Bantam and a 44\% lower injury rate in Pee Wee.${ }^{17} \mathrm{~A}$ systematic review and meta-analysis in Pee Wee report a pooled estimate of a $67 \%$ lower rate of concussion $(\mathrm{IRR}=0.33 ; 95 \% \mathrm{CI}$ : 0.25 to 0.45$)$ following such policy change. ${ }^{12}$ It is possible that the greater impact seen in younger Pee Wee players is related to the higher rate of concussion in a younger age group with more immature brains, poorer decisionmaking ability, earlier skill development or differences in body checking experience. The rates of injury (7.98 injuries/1000 game-hours) and concussion (3.34 concussions/1000 gamehours) are consistent with recently reported rates in Bantam. ${ }^{718}$ The increasing rates of concussion reported between 2008 and 2015 , however, may be related to greater concussion awareness, 
Table 4 Number and rates of game-related injuries per 1000 player-hours among Bantam hockey players in body checking and non-body checking leagues by location and type of injury

\begin{tabular}{|c|c|c|c|c|}
\hline \multirow{3}{*}{$\begin{array}{l}\text { Location and type of injury } \\
\text { Location }\end{array}$} & \multicolumn{4}{|c|}{ Rate per 1000 player-hours $(95 \% \mathrm{Cl})$ * } \\
\hline & \multicolumn{2}{|c|}{ Body checking } & \multicolumn{2}{|c|}{ No body checking } \\
\hline & $\mathrm{n}(/ 129)$ & Rate & $\mathrm{n}(/ 31)$ & Rate \\
\hline Head/face & 55 & $3.40(0.78$ to 6.02$)$ & 16 & $1.89(0.00$ to 4.59$)$ \\
\hline Neck/throat† & 3 & $0.19(0.04$ to 0.54$)$ & 2 & $0.24(0.03$ to 0.85$)$ \\
\hline Shoulder/clavicle & 12 & $0.74(0.00$ to 2.2$)$ & 0 & $0.00(0.00$ to 0.00$)$ \\
\hline Arm/elbow/forearm $†$ & 3 & 0.19 (0.04 to 0.54$)$ & 3 & 0.35 (0.07 to 1.04$)$ \\
\hline Wrist/hand & 10 & 0.62 (0.00 to 1.95$)$ & 1 & $0.12(0.00$ to 0.92$)$ \\
\hline Back/sidet & 5 & 0.31 (0.10 to 0.72$)$ & 0 & $0.00(0.00$ to 0.44$)$ \\
\hline Chest/ribs/abdoment & 3 & $0.19(0.04$ to 0.54$)$ & 1 & $0.12(0.00$ to 0.66$)$ \\
\hline Pelvis/hips/groin/ upper leg $\dagger$ & 3 & $0.19(0.04$ to 0.50$)$ & 3 & 0.35 (0.07 to 1.04$)$ \\
\hline Kneet & 6 & $0.37(0.14$ to 0.81$)$ & 1 & $0.12(0.00$ to 0.66$)$ \\
\hline Lower leg/ankle/foot† & 7 & $0.43(0.17$ to 0.89$)$ & 1 & 0.12 (0.00 to 0.66$)$ \\
\hline Othert & 0 & $0.00(0.00$ to 0.23$)$ & 1 & $0.12(0.00$ to 0.66$)$ \\
\hline Missing/unknown & 22 & $1.36(0.00$ to 3.28$)$ & 2 & 0.24 (0.00 to 1.34$)$ \\
\hline \multicolumn{5}{|l|}{ Type } \\
\hline Contusion & 9 & $0.56(0.00$ to 1.00$)$ & 4 & 0.47 (0.00 to 2.06$)$ \\
\hline Concussion & 54 & $3.34(0.76$ to 5.93$)$ & 17 & 2.01 (0.00 to 4.78$)$ \\
\hline Joint/ligament sprain/dislocation & 8 & $0.49(0.00$ to 1.69$)$ & 1 & 0.12 (0.00 to 0.92$)$ \\
\hline Fracture & 14 & 0.87 (0.00 to 2.38$)$ & 1 & $0.12(0.00$ to 0.89$)$ \\
\hline Muscle strain/tendinitis & 14 & 0.87 (0.00 to 2.44$)$ & 4 & 0.47 (0.00 to 2.08$)$ \\
\hline Abrasion/bleeding/ burn/cut/blister & 1 & $0.06(0.00$ to 0.34$)$ & 0 & $0.00(0.00$ to 0.44$)$ \\
\hline Othert & 5 & 0.31 (0.10 to 0.72$)$ & 2 & 0.24 (0.03 to 0.85$)$ \\
\hline Missing/unknown & 24 & $1.48(0.00$ to 3.45$)$ & 2 & 0.24 (0.00 to 1.32$)$ \\
\hline
\end{tabular}

${ }^{*}$ Crude rates with $95 \%$ Cls with a design effect that takes into account clustering (offset by game-hours).

\section{†Exact Cls.}

recognition, and education with increased media attention and public awareness of concussion over this period. ${ }^{18} 32$

Applying our estimates to the entire population of non-elite Bantam players in Alberta and Canada for one season, we estimate that 747 game-related injuries could be prevented in Alberta if body checking was disallowed in non-elite Bantam across Alberta and 6386 injuries in Canada if body checking were disallowed in non-elite Bantam nationally. Pee Wee estimates showed a reduction in 6388 injuries (4806 concussions) in Canada in Pee Wee at all levels. ${ }^{1}$

In this study, larger players (by weight) had a greater rate of injury in non-elite Bantam. Contrasting evidence in Pee Wee shows that smaller players had a greater rate of injury than larger players and there was no differential in rate of injury or concussion previously reported in Bantam. ${ }^{14} 1618$ Size differential may be more relevant for smaller players in Pee Wee due to a greater size disparity or body checking experience. Bantam players in this study had a median weight $(54 \mathrm{~kg})$ that is lower than that previously reported in elite Bantam $(60 \mathrm{~kg}) .{ }^{18} 19$ This may be related to selection criteria for elite teams biassing towards larger players and may explain the differential findings in this non-elite cohort of Bantam players. Players with a previous history of injury or concussion had a clinically relevant increased risk of injury and concussion in this study, but these findings were not statistically significant as in other cohorts. ${ }^{14-19}$ A larger sample size may have yielded a statistically significant finding. Being a goalie was protective of injury compared with defence players, consistent with other studies. ${ }^{14}$ 16-19 Year of play was not found to be a risk factor for injury or concussion in this study, inconsistent with previous studies where first year players were at greater risk of injury and concussion in Pee Wee and elite Bantam. ${ }^{14}$ 16-19 This difference may be related to speed of play in non-elite levels compared with elite Bantam.

\section{Limitations}

The estimated sample size was not met for the non-body checking cohort and the effect size for concussion was lower than anticipated. Concussions were included if they met the definition; however, not all players with a suspected concussion followed up with a physician (47/54 saw a physician $(87.0 \%)$ in body checking cohort and 10/17 (58.8\%) in non-body checking cohort). Bias may have been introduced in the IRR severe concussion estimates as return to play guidelines under physician management may have been affected. Other factors contributing to return to play decisions include the importance of a game, body checking policy, motivation, personality factors and parental influence. These may have influenced the precision of equating time loss with severity of injury. Protocols for return to play were established based on the International Consensus Statement on Concussion in Sport and facilitated consistency for return to play between clinics. ${ }^{22}$ It is possible that there was non-differential misclassification of concussion severity based on the 10-day time loss cut-point if there was a delay of greater than 3 days until the athlete had first seen a study physician and then progressed through the return to play protocol. Self-reported covariates may have been subject to recall bias and position of play may not have been consistent for every game during the season. Selection bias may be of concern based on teams' unwillingness to participate; however, the reason for non-participation was largely the inability to identify a team safety designate willing to support the injury surveillance throughout the season. Although socioeconomic status data were not collected, the inclusive sampling strategy across city associations and study years should minimise any potential confounding effect. 


\section{CONCLUSION}

Disallowing body checking in non-elite levels of Bantam was associated with a 54\% lower rate of game-injuries and $61 \%$ lower rate of severe injury. Point estimates showed a clinically relevant (though not statistically significant) $40 \%$ lower rate of concussion. Important considerations for future research include body checking skill development, body checking experience, coaching skills, skill progression and the impact of body checking policy on game contact behaviours and player performance. The public health impact of policy disallowing body checking in non-elite levels of play in Bantam is significant and further research to evaluate whether such policy change reduces injuries in non-elite levels of Midget (ages 15-17 years) is recommended.

\section{What are the new findings?}

- Policy change disallowing body checking in non-elite Bantam (13-14 years) ice hockey resulted in a 56\% lower rate of injury.

- Policy change disallowing body checking in non-elite Bantam ice hockey resulted in a $40 \%$ lower rate of concussion. This finding is clinically relevant, but not statistically significant.

- The public health impact of policy disallowing body checking in non-elite Bantam levels of play is substantial. We recommend further research to evaluate whether such policy change reduces injuries in non-elite levels of Midget (ages 15-17 years).

Acknowledgements The Sport Injury Prevention Research Centre is one of the International Research Centres for Prevention of Injury and Protection of Athlete Health supported by the International Olympic Committee. Carolyn Emery is supported by a Chair in Pediatric Rehabilitation (Alberta Children's Hospital Foundation). This research was possible due to the support from Hockey Calgary, Hockey Edmonton, BC Hockey, Hockey Alberta and Hockey Canada. This research could not have been completed without the support of many Bantam players, parents, coaches, team designates, physiotherapists, athletic therapists, student therapists and study physicians.

Contributors CAE, LPD, AMB, PE, KJS, SB, MM, CL, CG, AM and BEH contributed to the study proposal development. CAE, AMB, MK, NS and SK contributed to data collection, entry, and data cleaning. CAE, LPD, AMB, PE and BEH contributed to the data analysis and interpretation of study results. $S B, M M$ and $C B$ contributed to all aspects of data collection at study sites outside of Calgary. CAE and BEH contributed to acquisition of funding, study design and led all aspects of the cohort. All authors critically reviewed and edited the manuscript before submission.

Funding This study was funded by Alberta Innovates Health Solutions (Collaborative Research and Innovation Opportunities Program Grant \# 3685), the Canadian Institutes of Health Research (Institute of Neuroscience, Mental Health and Addictions Grant \#293332) and the Hotchkiss Brain Institute (University of Calgary).

Competing interests None declared.

Patient consent for publication Not required.

Ethics approval Ethics approval was received from the research ethics boards at the University of Calgary (Ethics ID: REB14-0348 and REB14-2209), University of Alberta (Ethics ID: REB Pro00024093) and the University of British Columbia (Ethics ID: CW14-0304/H14-01894).

Provenance and peer review Not commissioned; externally peer reviewed.

Data availability statement All data relevant to the study are included in the article or uploaded as supplementary information.

\section{ORCID iDs}

Carolyn Emery http://orcid.org/0000-0002-9499-6691

Amanda Marie Black http://orcid.org/0000-0001-5668-9706

Brent E Hagel http://orcid.org/0000-0002-5530-0639

\section{REFERENCES}

1. Annual Report 2015-2016. Hockey Canada, 2016. Available: https://az184419.vo. msecnd.net/hockey-canada/Corporate/About/Downloads/2015-16_annual_report_e. pdf [Accessed Nov 13 2017].
2. Taliaferro LA, Rienzo BA, Miller MD, et al. High school youth and suicide risk: exploring protection afforded through physical activity and sport participation. J Sch Health 2008;78:545-53.

3. Slutzky CB, Simpkins SD. The link between children's sport participation and selfesteem: exploring the mediating role of sport self-concept. Psychol Sport Exerc 2009;10:381-9.

4. Fox CK, Barr-Anderson D, Neumark-Sztainer D, et al. Physical activity and sports team participation: associations with academic outcomes in middle school and high school students. J Sch Health 2010;80:31-7.

5. Daneshvar DH, Nowinski CJ, McKee AC, et al. The epidemiology of sport-related concussion. Clin Sports Med 2011;30:1-17.

6. Rajabali F, Ibrahimova A, Turcotte K, et al. Concussion among children and youth in British Columbia. British Columbia injury research and prevention unit and child health British Columbia, 2013. Available: file:///C:/Users/Carolyn\%20Emery/Desktop/ October\%202018/15\%2006\%2022\%20Concussion\%20-\%20Children\%20and\% 20Youth\%20Supplement\%20FINAL.pdf [Accessed 3 Nov 2018].

7. Emery CA, Meeuwisse WH. Injury rates, risk factors, and mechanisms of injury in minor hockey. Am J Sports Med 2006;34:1960-9.

8. Emery CA, Meeuwisse WH, McAllister JR. Survey of sport participation and sport injury in Calgary and area high schools. Clin J Sport Med 2006;16:20-6.

9. Fridman L, Fraser-Thomas JL, McFaull SR, et al. Epidemiology of sports-related injuries in children and youth presenting to Canadian emergency departments from 20072010. BMC Sports Sci Med Rehabil 2013;5.

10. Emery $C A$, Hagel $B$, Decloe $M$, et al. Risk factors for injury and severe injury in youth ice hockey: a systematic review of the literature. Inj Prev 2010;16:113-8.

11. Pfister T, Pfister $K$, Hagel $B$, et al. The incidence of concussion in youth sports: a systematic review and meta-analysis. Br J Sports Med 2016;50:292-7.

12. Emery CA, Black AM, Kolstad $A$, et al. What strategies can be used to effectively reduce the risk of concussion in sport? A systematic review. Br J Sports Med 2017:51:978-84

13. McKay CD, Meeuwisse WH, Emery CA. Informing body checking policy in youth ice hockey in Canada: a discussion meeting with researchers and community stakeholders. Can J Public Health 2014;105:e445-9.

14. Emery CA, Kang J, Shrier I, et al. Risk of injury associated with body checking among youth ice hockey players. JAMA 2010;303:2265-72.

15. Lacny $S$, Marshall DA, Currie G, et al. Reality check: the cost-effectiveness of removing body checking from youth ice hockey. Br J Sports Med 2014;48:1299-305.

16. Black AM, Macpherson AK, Hagel BE, et al. Policy change eliminating body checking in non-elite ice hockey leads to a threefold reduction in injury and concussion risk in 11- and 12-year-old players. Br J Sports Med 2016;50:55-61.

17. Black AM, Hagel BE, Palacios-Derflingher $L$, et al. The risk of injury associated with body checking among Pee Wee ice hockey players: an evaluation of hockey Canada's national body checking policy change. Br J Sports Med 2017;51:1767-72.

18. Emery C, Kang J, Shrier I, et al. Risk of injury associated with bodychecking experience among youth hockey players. Can Med Assoc J 2011;183:1249-56.

19. Krolikowski MP, Black AM, Palacios-Derflingher $L$, et al. The Effect of the "Zero Tolerance for Head Contact" Rule Change on the Risk of Concussions in Youth Ice Hockey Players. Am J Sports Med 2017:45:468-73.

20. Hockey Canada. Teaching checking: body checking. checking resource guide. Available: https://cdn.hockeycanada.ca/hockey-canada/Hockey-Programs/Coaching/ Checking/Downloads/teaching_checking_progression_body_checking.pdf [Accessed 27 November 2018].

21. Benson BW, Meeuwisse WH, Rizos J, et al. A prospective study of concussions among national hockey League players during regular season games: the NHL-NHLPA concussion program. Can Med Assoc J 2011;183:905-11.

22. McCrory P, Meeuwisse W, Aubry M, et al. Consensus statement on concussion in sport-the 4th International Conference on concussion in sport held in Zurich, November 2012. Phys Med Rehab 2013;5:255-79.

23. Barlow KM, Crawford S, Stevenson A, et al. Epidemiology of postconcussion syndrome in pediatric mild traumatic brain injury. Pediatrics 2010;126:e374-81.

24. Fuller CW, Ekstrand J, Junge $A$, et al. Consensus statement on injury definitions and data collection procedures in studies of football (soccer) injuries. Clinical Journal of Sport Medicine 2006;16:97-106.

25. Broglio SP, Puetz TW, Peutz T. The effect of sport concussion on neurocognitive function, self-report symptoms and postural control : a meta-analysis. Sports Med 2008;38:53-67.

26. Iverson $\mathrm{G}$. Predicting slow recovery from sport-related concussion: the new simplecomplex distinction. Clin J Sport Med 2007;17:31-7.

27. Lau B, Lovell MR, Collins MW, et al. Neurocognitive and symptom predictors of recovery in high school athletes. Clin J Sport Med 2009;19:216-21.

28. Makdissi M. Is the simple versus complex classification of concussion a valid and useful differentiation? Br J Sports Med 2009;43 Suppl 1(Suppl_1):i23-7.

29. R Core Team. R: a language and environment for statistical computing. Vienna, Austria: R Foundation for Statistical Computing, 2013URL. http://www.R-project.org/

30. Stata Statistical Software (computer software) [program]. Release 10.0 version. College Station, TX: Stata Corporation, 2005.

31. Kang J, Yuan Y, Emery C. Assessing remedies for missing Weekly individual exposure in sport injury studies. Inj Prev 2014;20:177-82. 


\section{Original research}

32. Hockey Canada Annual Report 2016-17. Available: https://cdn.hockeycanada.ca/hockeycanada/Corporate/About/Downloads/2016-17-annual-report-e.pdf [Accessed Oct 2018]. 